\title{
Gentamicin induced Anaphylaxis, a case report
}

\author{
Catalina María Gómez Henao ${ }^{*}$, Cristina Isabel Herrera Morales', Ricardo Cardona Villa², Ana Maria Celis Henao ${ }^{1}$ \\ From 3rd WAO International Scientific Conference (WISC) 2014 \\ Rio de Janeiro, Brazil. 6-9 December 2014
}

\section{Introduction}

The aminoglycosides are a group of antibiotics widely used, adverse reactions to these drugs have frequently been reported, mainly toxic (ototoxicity and nephrotoxicity); hypersensitivity reactions that occur more often are contact dermatitis, generally to ophthalmic and otic Neomycin and Gentamicin preparations, however, hypersensitivity reactions mediated by IgE, have been recently reported, founding in the literature only a few case reports of these.

\section{Objective}

Present a case of type I hypersensitivity reaction to Gentamicin.

\section{Methods}

A systematic literature research was conducted in databases PubMed, Embase and Lilacs, using keywords: Anaphylaxis and Gentamicin, Gentamicin and Hypersensitivity and Anaphylaxis Aminoglycosides; founding just three case reports of anaphylaxis induced by Gentamicin in the literature; then one case report of a patient with type I hypersensitivity reaction after administration of gentamicin Intramuscular, attended in allergy service in MedellinColombia is performed

\section{Results}

We report a case of a female patient, 53 years old, referred to the allergy clinic service with an adverse reaction after application of gentamicin IM for clinic study. The patient was in treatment, for a superinfected third degree burn, with intramuscular gentamicin once daily for 8 days. One day after the last dose presented urticaria with angioedema and respiratory distress. After two months of these symptoms skin tests were performed with Gentamicin, prick test with a concentration of $40 \mathrm{mg} / \mathrm{ml}$ with negative reading after 20 minutes, positive control to histamine. Subsequently Intradermal test was performed with a concentration of $0,2 \mathrm{mg} / \mathrm{ml}$ with positive reading after 20 minutes.

\section{Conclusion}

Although rare IgE-mediated reactions to aminoglycosides may occur, skin tests being a useful tool for diagnosis.

\section{Consent}

Written informed consent was obtained from the patient for publication of this abstract and any accompanying images. A copy of the written consent is available for review by the Editor of this journal.

\section{Authors' details \\ 'Universidad De Antioquia, Colombia. ${ }^{2}$ I.P.S Universitaria-Clinica León XIII,} Colombia.

Published: 8 April 2015

\section{References}

1. Schulze S, Wollina U: Gentamicin-induced anaphylaxis. Allergy 2003, 58(1):88-9.

2. Connolly M, McAdoo J, Bourke JF: Gentamicin-induced anaphylaxis. Ir J Med Sci 2007, 176:317-318.

doi:10.1186/1939-4551-8-S1-A269

Cite this article as: Henao et al:: Gentamicin induced Anaphylaxis, a case report. World Allergy Organization Journal 2015 8(Suppl 1):A269.

Universidad De Antioquia, Colombia

Full list of author information is available at the end of the article 